\title{
Corrigendum: Controlling hybrid nonlinearities in transparent conducting oxides via two-colour excitation
}

\author{
M. Clerici, N. Kinsey, C. DeVault, J. Kim, E.G. Carnemolla, L. Caspani, A. Shaltout, D. Faccio, V. Shalaev, \\ A. Boltasseva \& M. Ferrera
}

Nature Communications 8:15829 doi: 10.1038/ncomms15829 (2017); Published 9 Jun 2017; Updated 1 Aug 2017

An incorrect version of the Supplementary Information was inadvertently published with this Article, where the pump wavelengths for panels $\mathrm{a}$ and $\mathrm{b}$ were interchanged in the figure caption of Supplementary Fig. 3. The HTML has now been updated to include the correct version of the Supplementary Information. 